Research Paper

\title{
Pim-3 Regulates Stemness of Pancreatic Cancer Cells via Activating STAT3 Signaling Pathway
}

\author{
Ting $\mathrm{Li}^{1}$, Zhen Wang ${ }^{2}$, Yi-feng Hou ${ }^{1 凶}$, and Ying-yi $\mathrm{Li}^{2 \bowtie}$ \\ 1. Department of Breast Surgery, Fudan University Shanghai Cancer Center, Department of Oncology, Shanghai Medical College, Fudan University, \\ Shanghai, China; \\ 2. Cancer Research Institute, Fudan University Shanghai Cancer Center, Department of Oncology, Shanghai Medical College, Fudan University, Shanghai, \\ China.
}

$\triangle$ Corresponding authors: Ying-yi Li, Cancer Research Institute, Fudan University Shanghai Cancer Center, 270 DongAn Road, Fudan University, Shanghai 200032, China. Tel.: +86-21-64175590-85220; Fax: +86-21-64172585; Email: liyingyi@fudan.edu.cn; Yi-feng Hou, Department of Breast Surgery, Fudan University Shanghai Cancer Center, 270 DongAn Road, Fudan University, Shanghai 200032, China. Tel.: +86-21-64175590-88806; Email: newmailhou@163.com

( ) Ivyspring International Publisher. This is an open access article distributed under the terms of the Creative Commons Attribution (CC BY-NC) license (https://creativecommons.org/licenses/by-nc/4.0/). See http://ivyspring.com/terms for full terms and conditions.

Received: 2016.12.05; Accepted: 2017.02.27; Published: 2017.06.02

\begin{abstract}
Due to its aggressiveness and unusual resistance to conventional therapies, pancreatic cancer is a highly lethal gastrointestinal malignancy with poor prognosis. According to the cancer stem cell hypothesis, there exists a fraction of cancer cells, that is, cancer stem cells, responsible for tumor maintenance and therapeutic failure. Herein we investigated the involvement of proto-oncogene Pim-3 in driving the stemness properties in pancreatic cancer. Expression levels of several stemness-associated markers were examined in several pancreatic cancer cell lines. The double positive (CD24+ESA+) and double negative (CD24-ESA-) pancreatic cancer cells were isolated from PANC-1 and L3.6pl, and their self-renewal ability, tumorigenicity as well as sensitivity to gemcitabine were then evaluated. Results showed that there existed heterogeneity in expression levels of stemness-associated surface markers among pancreatic cancer cell lines. CD24+ESA+ pancreatic cancer cells exhibited increased tumorigenicity and decreased chemosensitivity to gemcitabine as compared to CD24-ESA- cells. Besides, the double positive (CD24+ESA+) subpopulation also exhibited greater expression level of Pim-3 when compared with the double negative (CD24-ESA-) ones. Furthermore, silencing of Pim-3 in pancreatic cancer cells leads to decreased proportions of both single positive (CD24+ and ESA+) and double positive (CD24+ESA+) pancreatic cancer cells. Overexpression of Pim-3 was associated with increased levels of some stemness-associated transcription factors (STAT3, etc.). Moreover, the phosphorylation level and transcriptional activity of STAT3 were decreased in Pim-3 silenced pancreatic cancer cells and restoration of its activity results in restitution of stem cell-like phenotypes. Therefore, Pim-3 maintains stemness of pancreatic cancer cells via activating STAT3 signaling pathway and might be used as a novel therapeutic target in pancreatic cancer.
\end{abstract}

Key words: Pim-3, stemness, chemoresistance, STAT3, pancreatic cancer.

\section{Introduction}

Pancreatic cancer (PC) is one of the gastrointestinal malignancies with extreme poor prognosis. In recent years, PC incidence has been on a rise worldwide, however its 5-year survival rate still remains around 5\%, and it's the fourth leading cause of cancer-related death in the United States [1]. Late diagnoses and unusual resistance to currently available therapeutic options are believed to be the main causes of high mortality in PC patients $[2,3]$. Therefore, continuous efforts should be made to gain an insight into disease progression and therapeutic resistance, and uncover novel biomarkers and therapeutic targets to enable early detection and effective treatment for pancreatic cancer.

Cancer stem cells (CSCs), a small subgroup of cells within the tumor capable of self-renewal and differentiation [4], contributes to tumor initiation, progression, therapeutic resistance and tumor recurrence [5]. Pancreatic CSCs were isolated based on cell surface markers (CD24, CD44 and ESA) for the 
first time in 2007, and proved to be high tumorigenic [6]. Subsequent studies attributed the high frequency of relapse and chemoresistance in PC to CSCs $[7,8]$, suggesting that effective tumor eradication would require promising agents that can target CSCs. However, the underlying molecular mechanisms and potential genetic drivers modulating pancreatic CSCs still remain to be uncovered.

Pim-3, a serine/threonine kinase, is involved in many cellular processes, including cell proliferation, survival and apoptosis [9]. Although Pim-3 is expressed in normal vital organs, it is overexpressed particularly in precancerous and cancerous lesions of endoderm-derived organs, including liver, pancreas, stomach and colon [10-13]. Previous studies have demonstrated that Pim-3, as an oncogene, could regulate proliferation, survival, angiogenesis [14] and apoptosis [11] of PC cells. Inhibition of Pim-3 kinase increases the sensitivity of pancreatic cancer cells to both chemotherapy and radiotherapy [15-17]. Moreover, Pim-3 plays an important role in sustaining the stem cell properties of mouse embryonic cells [18] and upregulation of the mRNA expression level of Pim-3 in glioblastoma stem cells has been observed when compared with neural stem cells [19]. However, till now there is no evidence associating Pim-3 expression with pancreatic CSC phenotypes.

In this study, we investigated the role of Pim-3 in the maintenance of stemness in PC. The data demonstrate that there exists heterogeneity in expression levels of stemness-associated surface markers among PC cell lines, and stem cell-like PC cells sorted based on surface markers show increased self-renewal ability and chemoresistance. Meanwhile, Pim-3 is overexpressed in stem cell-like PC cells and its expression has a positive correlation with expression levels of stemness-associated surface markers expression levels. Furthermore, Pim-3 was shown to promote stem cell-like phenotypes through activating STAT3 signal pathway in PC. These findings provide firsthand experimental evidence for the involvement of Pim-3 in regulating stemness of PC and further support its clinical use as a novel therapeutic target.

\section{Methods}

\section{Cell culture}

MIAPaCa-2 was cultured in RPMI 1640, PANC-1 was cultured in Dulbecco's modified essential medium (DMEM) and L3.6pl was cultured in minimum essential medium (MEM). All culture medium is supplemented with $10 \%$ fetal bovine serum (Biosera) and antibiotics. Cells expressing high levels of CD24 and ESA were isolated from PANC-1 and L3.6pl and then cultured in ultra-low attachment plate (Corning) in stem cell culture medium (DMEM/F12, Hycolone) supplemented with Knockout Serum Replacement (KSR, Gibco), basic fibroblast growth factor (bFGF; $20 \mathrm{ng} / \mathrm{mL}$ ) and epidermal growth factor (EGF; $20 \mathrm{ng} / \mathrm{mL}$ ) (PeproTech), penicillin (100 units $/ \mathrm{mL})$ and streptomycin $(100 \mu \mathrm{g} / \mathrm{mL})$ to maintain their undifferentiated status. Cells were maintained at 37 ${ }^{\circ} \mathrm{C}$, in a humidified atmosphere containing $5 \% \mathrm{CO}_{2}$.

\section{Immunoblotting}

Immunoblotting was performed as described previously [20]. $\beta$-actin was used as endogenous control for total protein. All primary antibodies and secondary antibodies were diluted following the manufacturer's instructions. The signals were detected using ImageQuant LAS 4000mini (GE Healthcare Life Science).

\section{Flow cytometry analysis and cell sorting}

Phycoerythrin (PE)-conjugated CD133 and CD24, fluorescein isothiocyanate (FITC)-conjugated CD44 and allophycocyanin (APC)-conjugated ESA antibodies (Miltenyi Biotech) were used to stain cells according to the manufacturer's instructions. Flow cytometry analysis was conducted with CytomicsTM FC 500 (Beckman Coulter) and done with FlowJo software. Flow cytometry cell sorting was conducted with MoFlo XDP (Beckman Coulter) and both CD24+ESA+ cells and CD24-ESA- cells were isolated from PANC-1 and L3.6pl.

\section{Colony and sphere formation assays}

For colony formation assay, 500 cells were seeded in the 6-well plate containing complete culture medium and cultured for two weeks. After fixed with $4 \%$ paraformaldehyde and stained with crystal violet, colonies ( $\geq 50$ cells) were counted and photographed using GelCount (Oxford Optronix). For sphere formation assay, $100 \mathrm{CD} 24+\mathrm{ESA}+$ or CD24-ESA- cells were seeded in the 96-well ultra-low attachment plate in $100 \mu \mathrm{L}$ of semi-solid stem cell culture medium $(1 \%$ methyl cellulose). After 10 days, spheres with a diameter larger than $50 \mu \mathrm{m}$ were counted and photographed using phase contrast microscope (Olympus).

\section{Mouse xenograft model}

Ten female BALB/c nude mice (aged 5 weeks) obtained from Shanghai SLACK Laboratory Animals (Shanghai, China) were randomly divided into two groups and were inoculated subcutaneously with $1 \times 10^{5}$ CD24+ESA+ or CD24-ESA- cells sorted from PANC-1 into the left flank of mice. During the course of the experiment, tumor growth was measured using 
calipers once a week. Tumor volume was calculated by the formula $\left(\right.$ length $\times$ width $\left.^{2}\right) / 2$. Nine weeks after tumor cells injection, tumor tissues were removed for further analyses. This study was carried out in strict accordance with the recommendations in the Guide for the Care and Use of Laboratory Animals of Fudan University. The protocol was approved by the Committee on the Ethics of Animal Experiments of Fudan University (Permit Number, SYXK (Hu) 2009-0082).

\section{Cell viability assay}

$8 \times 10^{3}$ CD24+ESA+ or CD24-ESA- PC cells or parental PC cells were seeded into the 96-well plate and were treated with gemcitabine in different concentrations the next day. After treatment for three days, cell viability was determined using Cell Counting Kit (Yeasen, Shanghai, China), according to the manufacturer's instructions. Survival rate was calculated according to the cell viability value.

\section{Quantitative Real-time PCR}

Total RNA was extracted using the TRNzol reagent (TIANGEN). mRNA was reversely transcribed using the PrimeScript ${ }^{\mathrm{TM}}$ RT reagent Kit with gDNA Eraser (TaKaRa) according to the manufacturer's instructions. Quantitative RT-PCR was performed using the Applied Biosystems HT7900 PCR system with SYBR ${ }^{\circledR}$ Premix Ex Taq ${ }^{\mathrm{TM}}$ (TaKaRa). Primer sequences for quantitative RT-PCR were shown in Table S1. Relative expression level of target genes was analyzed by the $\Delta \Delta \mathrm{Ct}$ method.

\section{Dual luciferase reporter assay}

Cells were seeded in 96-well plates at a density of $1 \times 10^{4}$ cells/well and transiently co-transfected with a mixture of Renilla plasmid and the STAT3 luciferase reporter construct using Lipofectamine 2000 reagent (Invitrogen) on the next day. The cells were lysed in passive lysis buffer provided by Dual-Glo Luciferase Assay System (Promega) 48h after transfection. The Renilla and firefly luciferase luminescence were measured using the Dual-Glo Luciferase Assay System (Promega).

\section{Statistical analysis}

Statistical analysis was performed with GraphPad Prism6 statistical software. Group comparisons of normally distributed data were performed using t-tests (two samples) or one-way ANOVA (multiple comparisons). Data were expressed as "means \pm SD" and $\mathrm{P}<0.05$ was considered statistically significant. Each experiment was performed at least three times.

\section{Results}

\section{Expression levels of several stemness-associated surface markers in PC cell lines}

A wide array of surface markers has been reported to be used to isolate and identify pancreatic CSCs, using single-labeled, double-labeled or even triple-labeled method. Therefore, we first examined expression levels of several stemness-associated surface markers, viz. CD133, CD24, CD44 and ESA, among PC cell lines. ESA (Epithelial Specific Antigen), also called epithelial cell adhesion molecular, is a transmembrane glycoprotein mediating

Ca2+-independent homotypic cell-cell adhesion in epithelia. In 2007, it was used for the first time as a stemness-associated surface marker to isolate pancreatic CSCs [6]. ESA is also involved in cell signaling [21], migration [22], proliferation [23], and differentiation [24]. Results from Western Blot (Figure 1A) and flow cytometry (Figure 1B) were consistent, showing that expression levels of these stemness-associated surface markers not only varied in the same cell line, but also varied from cell line to cell line. Surface markers expressed by a majority (approximately $100 \%$ ) or a minority (approximately $0 \%$ ) were supposed not suitable for subsequent studies. Therefore, we chose two markers (CD24 and ESA) for further investigation.

\section{CD24+ESA+ PC cells show higher self-renewal ability and tumorigenicity compared to CD24-ESA- PC cells}

Double positive (CD24+ESA+) and double negative (CD24-ESA-) PC cells were isolated from PANC-1 and L3.6pl by flow cytometry using double-labeled method. Apparently, 22.5\% PANC-1 cells and $\sim 3.32 \%$ L3.6pl cells (Figure 2A) were double positive while the fraction of double negative was $\sim 22.9 \%$ and $\sim 91.1 \%$ (Figure $2 \mathrm{~A}$ ) in PANC-1 and $\mathrm{L} 3.6 \mathrm{pl}$, respectively. We next sought to investigate these of CD24+ESA+ PC cells and CD24-ESA- PC cells in self-renewal and tumor propagation potentials, the hallmarks of CSCs, using colony formation assay, sphere formation assay and animal xenograft model. We observed more colonies and spheres formed in CD24+ESA+ PANC-1 cells as compared to CD24-ESA- PANC-1 cells (Fig. 2B and Fig. 2C), indicating higher self-renewal ability of CD24+ESA+ PANC-1 cells. Same results were drawn from L3.6pl (Figure 2B and Figure 2C). In the animal xenograft model, after inoculating $1 \times 10^{5}$ CD24+ESA+ or CD24-ESA- PANC-1 cells subcutaneously into the left flank of mice nine weeks, four mice in five injected with CD24+ESA+ PANC-1 cells developed tumor, 
whereas only one mice in five injected with CD24-ESA- PANC-1 cells developed tumor (Figure 2D), demonstrating higher tumorigenicity of CD24+ESA+ PANC-1 cells. Meanwhile, the average tumor volume of CD24+ESA+ group was significantly bigger than that of CD24-ESA- group (Figure 2D).
Therefore, PC cells expressing both CD24 and ESA $(\mathrm{CD} 24+\mathrm{ESA}+)$ are considered as stem cell-like cells while cells with no or negligible expression (CD24-ESA-) are considered as non-stem cell-like cells.

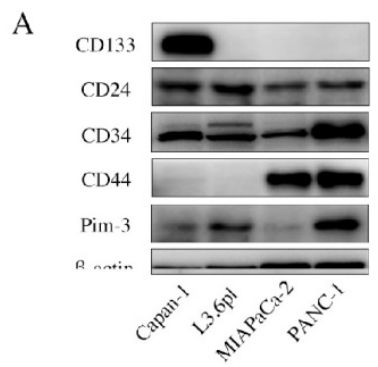

B
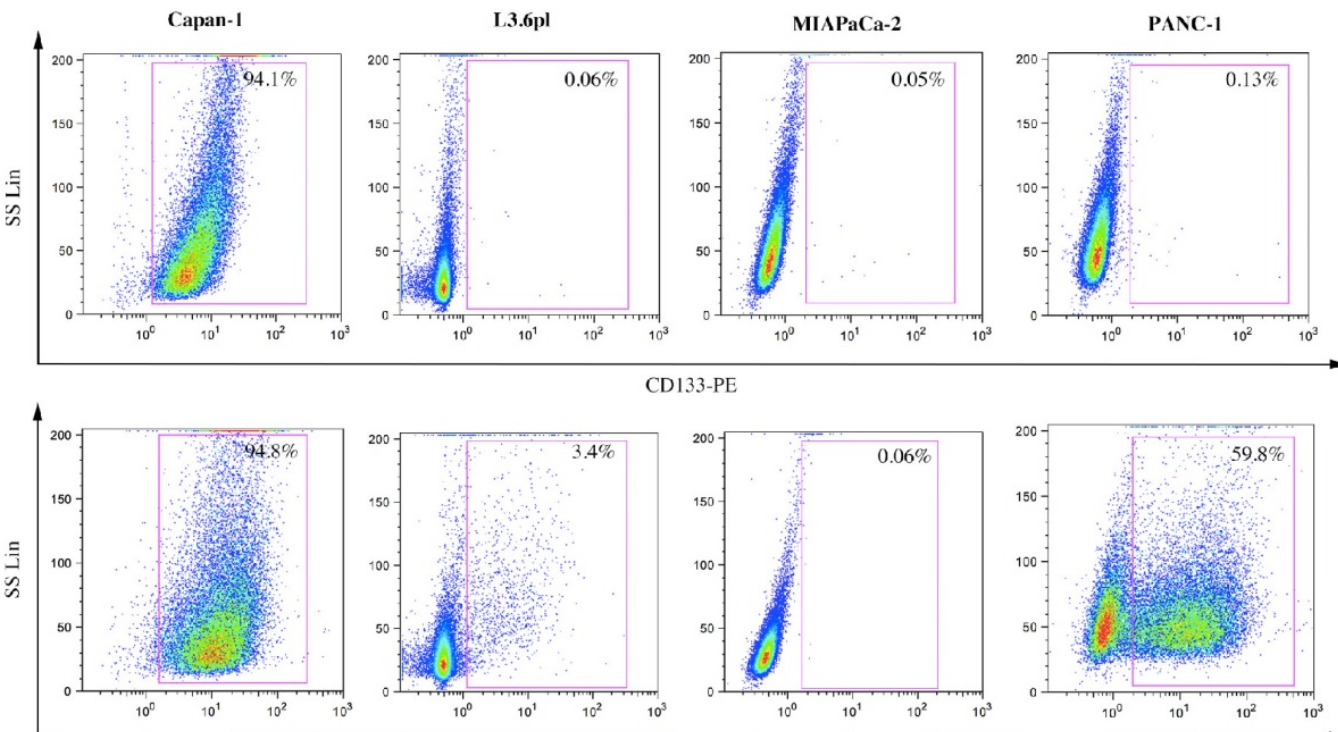

CD24-PE
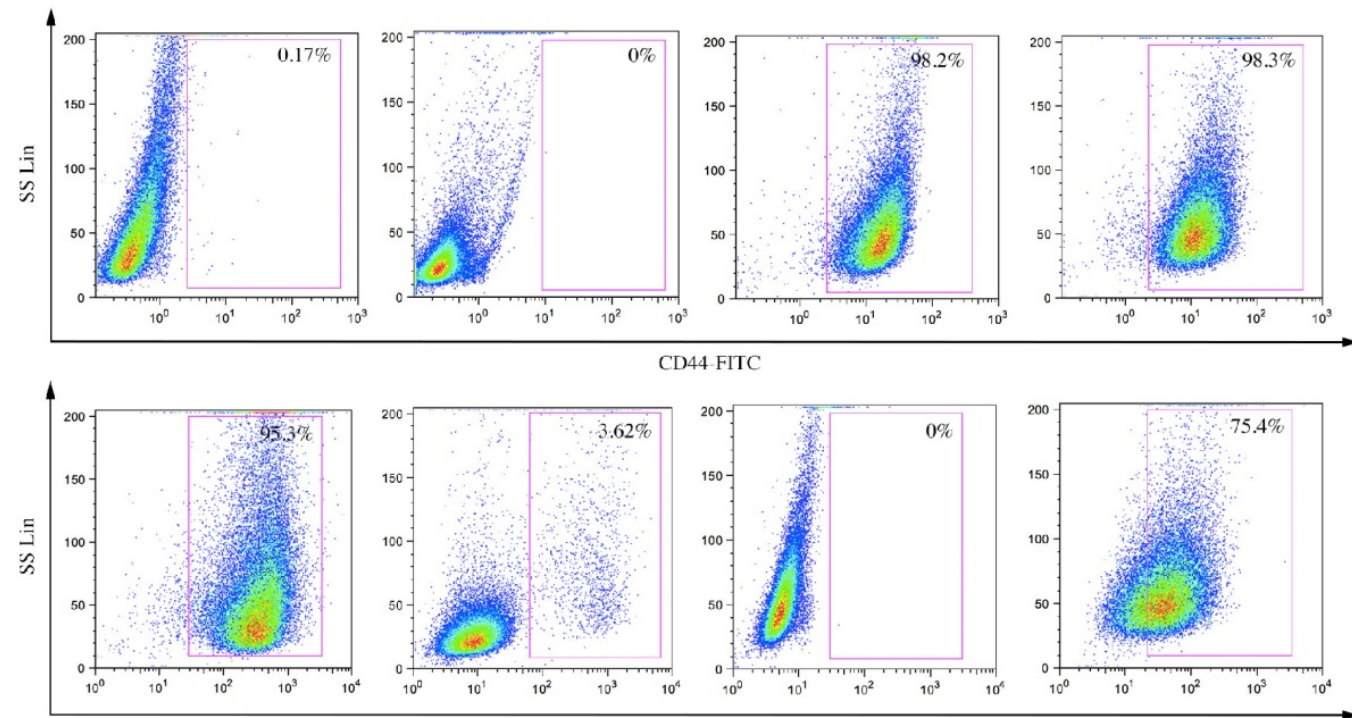

ESA-APC

Figure 1. Expression levels of several stemness-associated surface markers in PC cell lines. $A, C D 133, C D 24, C D 34, C D 44$ and Pim-3 expression in human PC cell lines were detected by immunoblotting. $\beta$-actin was used as internal control. B, PC cells were incubated with fluorochrome-conjugated CD133, CD24, CD44 and ESA antibodies and subjected to flow cytometry analysis. Cells expressing specific markers were drawn in the rectangle gate as well as their percentage in total cells. 
A

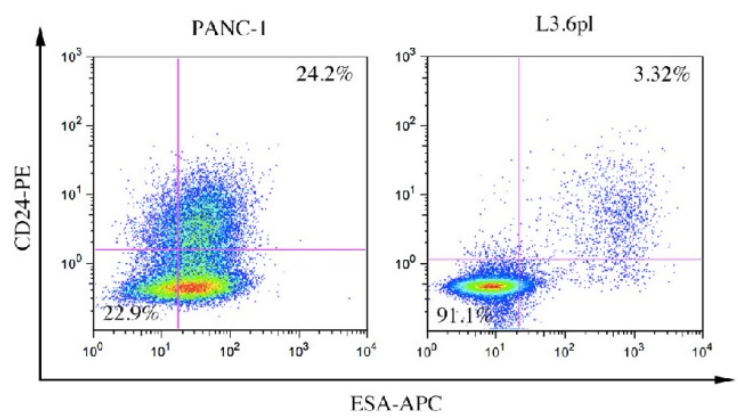

B

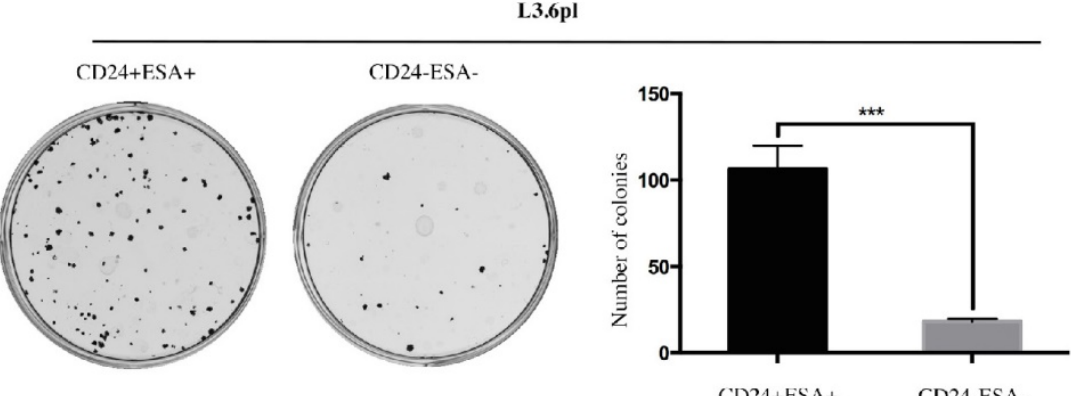

CD24+ESA+

CD24-ESA

PANC-1
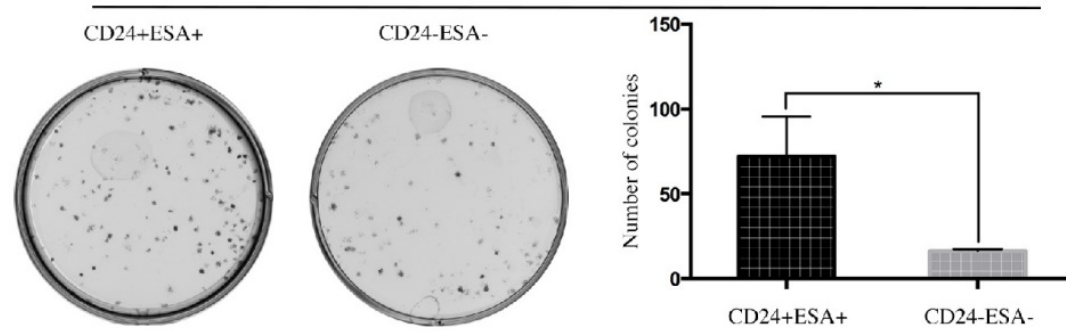

C

L3.6pl
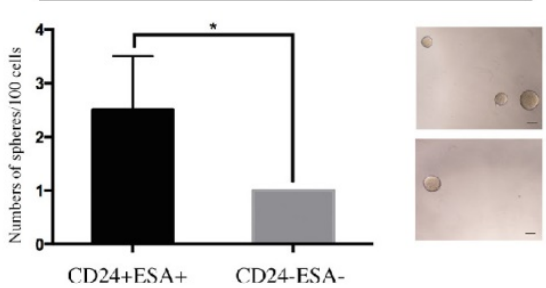

CD24+ESA

CD24-ESA-

PANC-1

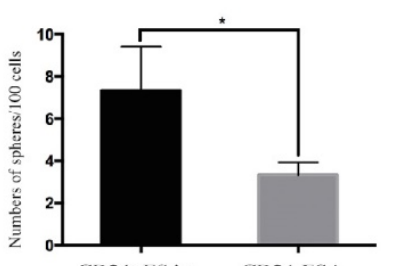

$\mathrm{CD} 24+\mathrm{ESA}+$ CD24-ESA-

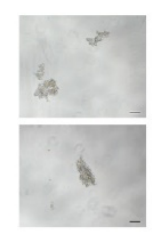

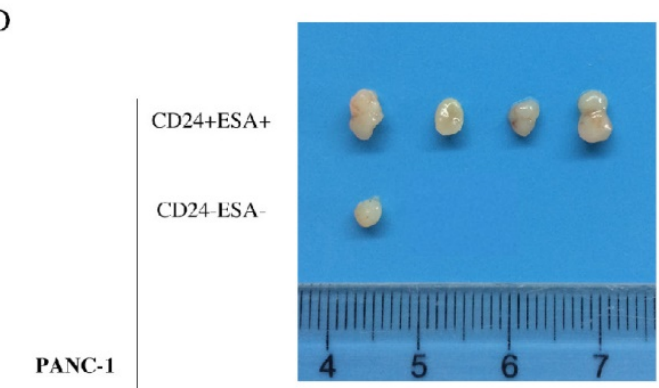

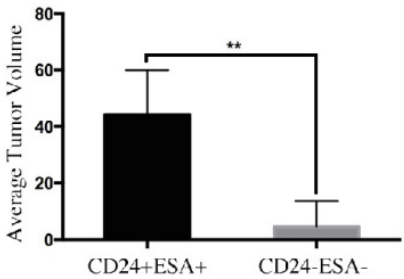

Figure 2. CD24+ESA+ PANC-1 cells show stem-cell like phenotypes. A, PANC-1 and L3.6pl cells were simultaneously labeled with PE-conjugated CD24 and APC-conjugated ESA and then analyzed using flow cytometry. B, Colony formation assay was performed using CD24+ESA+ and CD24-ESA- PANC-1 cells and L3.6pl cells. CD24+ESA+ and CD24-ESA- cells were sorted from PANC-1 and L3.6pl respectively using flow cytometry. The colonies were counted 2 weeks after plantation. Data are expressed as the mean \pm SD of three independent experiments. $* \mathrm{P}<0.05, * * * \mathrm{P}<0.001$. C, CD24+ESA+ and CD24-ESA-PANC-1 cells and L3.6Pl cells were seeded in ultra-low attachment 96 -well plate respectively and allowed to grow for 10 days in stem cell culture medium. Spheres $(>50 \mu \mathrm{m})$ were counted and photographed. Data represent the mean \pm SD of three independent experiments. $* P<0.05$. D, Tumor number and tumor size in mice 9 weeks after received subcutaneous injection of CD24+ESA+ and CD24-ESA- PANC-1 cells. Data are presented as the mean $\pm S D ; n=5 ; * * P<0.01$. 


\section{CD24+ESA+ PC cells exhibits the chemo-resistance to gemcitabine cytotoxicity}

It has been well evidenced that human PC consists of a small subset of cells, known as CSCs, which is relatively resistant to gemcitabine, a conventional chemotherapeutic agent in PC treatment [25]. To examine the role of stem cell-like cells in chemoresistance, CD24+ESA+ and CD24-ESA- PC cells were treated with increasing doses of gemcitabine for three days, and then cell viability and survival rate were evaluated. Data showed that CD24+ESA+ cells were less sensitive to gemcitabine cytotoxicity as compared to CD24-ESA- cells in
PANC-1 and L3.6pl PC cells (Figure 3A and 3B). Moreover, after treated with gemcitabine, the percentage of L3.6pl cells expressing CD24 was elevated from $4.56 \%$ to $17.6 \%$ and the percentage of ESA+ L3.6pl cells was elevated from 3.93\% to $21.2 \%$ (Figure 3C). Similar results were drawn from MIAPaCa-2 (Figure 3D), and the expression of CD24 and ESA were elevated from $0.06 \%$ to $0.85 \%$ and from $0 \%$ to $0.12 \%$ respectively. Taken together, our findings further confirm that CD24+ESA+ cells constitute stem cell-like phenotypes in PC, a source of resistance to conventional chemotherapy.
A

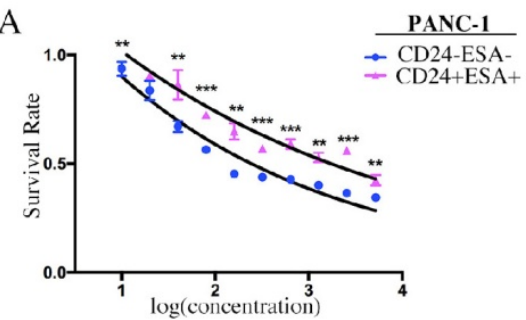

$\mathrm{C}$
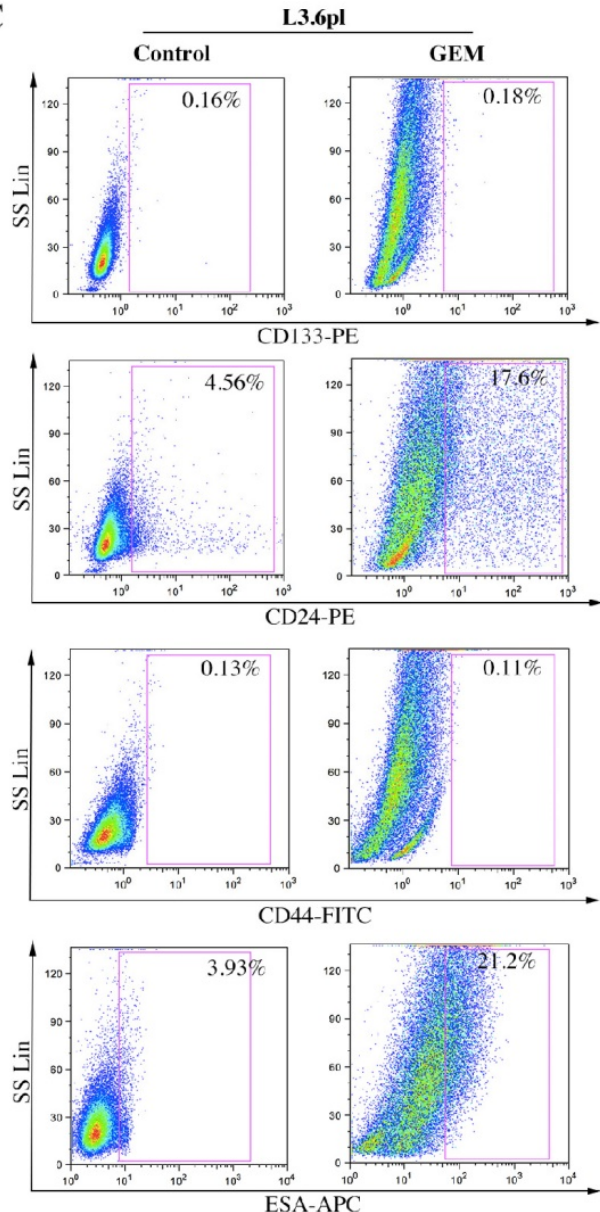

B

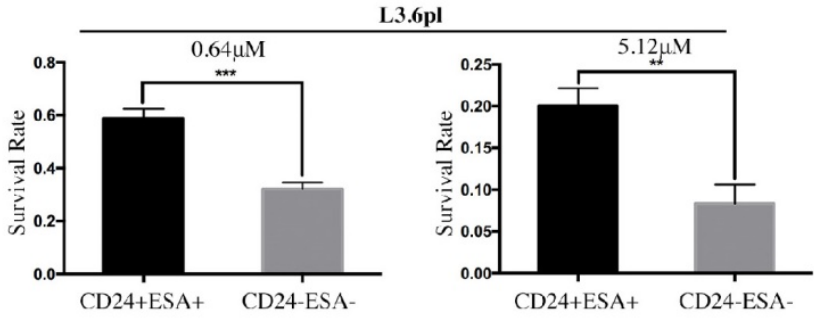

D
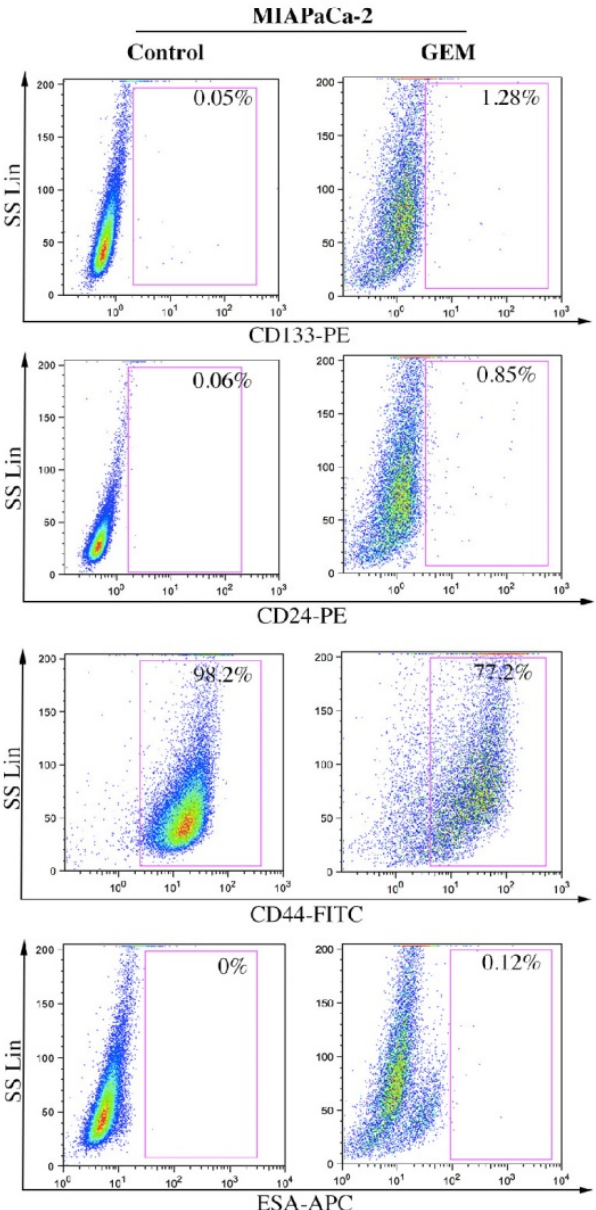

Figure 3. $C D 24+E S A+P C$ cells exhibit gemcitabine chemoresistance. $\boldsymbol{A}$ and $B, C D 24+E S A+P C$ cells were less sensitive to gemcitabine treatment. The double positive and double negative PANC-1 cells and L3.6pl cells were treated with increasing concentrations of GEM for $72 \mathrm{~h}$ respectively. Cell viability was determined by CCK-8. Data are expressed as the mean \pm SD. The experiments were repeated three times. **P $<0.01$, ***P $<0.001$. The percentage of CD24+ESA+ PC cells

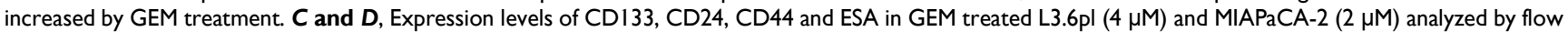
cytometry. Cells expressing specific markers were drawn in the rectangle gate as well as their percentage in total cells. 


\section{Pim-3 enhances stem cell-like phenotypes in PC cells}

Pim-3-silenced stable cell line (PANC-1-Pim3-sh) and Pim-3-overexpressed stable cell line (MIAPaCa-2-Pim3) have been successfully generated previously by our research team [17]. To investigate the role of Pim-3 in maintaining stemness of PC cells, we first analyzed the expression levels of stemness-associated markers in PANC-1-Pim-3-sh and MIAPaCa-2-Pim3 compared with parent cells. Data showed that the percentage of single positive cells (CD24+ / ESA+) and double positive cells $(\mathrm{CD} 24+\mathrm{ESA}+)$ in PANC-1-Pim-3-sh decreased drastically as compared to parent PANC-1 (Figure $4 \mathrm{~A})$. In contrast, compared to MIAPaCa- 2 parent cells, the percentage of CD24+ cells and ESA+ cells were both increased in MIAPaCa-2-Pim-3 cells (Figure 4A). Results above were further supported by Western Blot and Real-time PCR analysis (Figure $4 \mathrm{~B}$ and $4 \mathrm{C}$ ). Several stemness-associated proteins or genes (BMI1, CD24, CD34, CD44, CXCR4, ESA, Oct-4, etc.) were downregulated in PANC-1-Pim-3-sh and were upregulated (except CD34) in MIAPaCa-2-Pim-3 as compared to their parent cells (Figure 4B and 4C). Furthermore, we confirmed that the expression levels of Pim-3 and these stemness-associated proteins or genes were remarkably higher in CD24+ESA+ PNAC-1 cells as compared to CD24-ESA- PANC-1 cells (Figure 4D). In addition, we observed that lesser spheres were formed by PANC-1-Pim-3-sh and more spheres were formed by MIAPaCa-2-Pim-3 when compared with their parent cells respectively (Figure 4E). Taken together, these findings suggest that Pim-3 could enhance stem cell-like phenotypes in PC cells.

\section{Pim-3 maintains stemness of PC cells via activating STAT3 signaling pathway}

Signal transducer and activator of transcription 3 (STAT3) is constitutively active in pancreatic cancer and many other cancer types, which play an important role in maintaining CSCs properties. We observed that the mRNA levels of several transcriptional factors, including STAT3, were upregulated in CD24+ESA+ PANC-1 cells (Figure S1A). We next examined the effect of Pim-3 on the phosphorylation and transcriptional activity of STAT3 using Western Blot and luciferase reporter assay. M-110 is a highly selective inhibitor of Pim kinase members (Pim-1, Pim-2 and Pim-3), but with preference for Pim-3[26]. Compared to parent PANC-1cells, significantly decreased phosphorylation of STAT3 in PANC-1-Pim-3-sh as well as PANC-1 treated with M-110 was observed (Fig. 5A). Similarly, phosphorylation of STAT3 was drastically increased in MIAPaCa-1-Pim-3; however, in MIAPaCa-1-Pim-3 treated with M-110, phosphorylation of STAT3 could barely be observed (Figure 5A). Data from dual luciferase assay showed that the transcriptional activity of STAT3 was slightly decreased in PANC-1-Pim-3-sh and was increased in MIAPaCa-2-Pim-3 as compared their parent cells (Figure 5B), which were further confirmed in HEK 293T cells (Figure S1B). To validate the involvement of STAT3 in Pim-3-induced stemness in PC cells, high Pim-3 expressing cells (MIAPaCa-2-Pim-3) were transiently transfected with STAT3 siRNA, in contrast, low Pim-3 expressing cells (PANC-1-Pim-3-sh) were transiently transfected with STAT3 plasmid (Figure 5C). Then expression levels of stemness-associated markers in these two treated cells were analyzed respectively by flow cytometry. Our data demonstrated that the percentage of MIAPaCa-2-Pim-3 cells expressing CD24 was decreased from $0.38 \%$ to $0.14 \%$ and the percentage of ESA+ MIAPaCa-2-Pim-3 cells was decreased from $0.27 \%$ to $0.09 \%$ (Figure 5D). While, to PANC-1-Pim-3-sh, the percentage of both single positive and double positive cells were elevated (Figure 5D). Taken together, our findings suggest that Pim-3 maintains stemness in PC cells via activation of STAT3, which could be effectively reversed by Pim-3 inhibition.

\section{Discussion}

Despite advances in comprehensive treatment for PC, the mortality still remains high due to late diagnosis and lack of effective therapies. Chemotherapy is the most common treatment for patients presenting with advanced PC [27], but drug resistance is often a limiting factor in successful chemotherapy. Intrinsic and acquired drug-resistance are believed to be major causes of chemotherapy failure in PC $[2,28]$. Accumulating evidence attribute therapy resistance, tumor metastasis and tumor recurrence to CSCs [29], characterized by high expression of multiple stemness-associated surface markers (viz., CD24, CD44, CD133 and ESA in PC). Therefore, development of novel therapeutic strategies capable of inhibiting or eliminating CSCs is believed to improve clinical outcomes of PC patients and furthermore, revelation of underlying mechanisms regulating CSCs appears particularly important. 
A
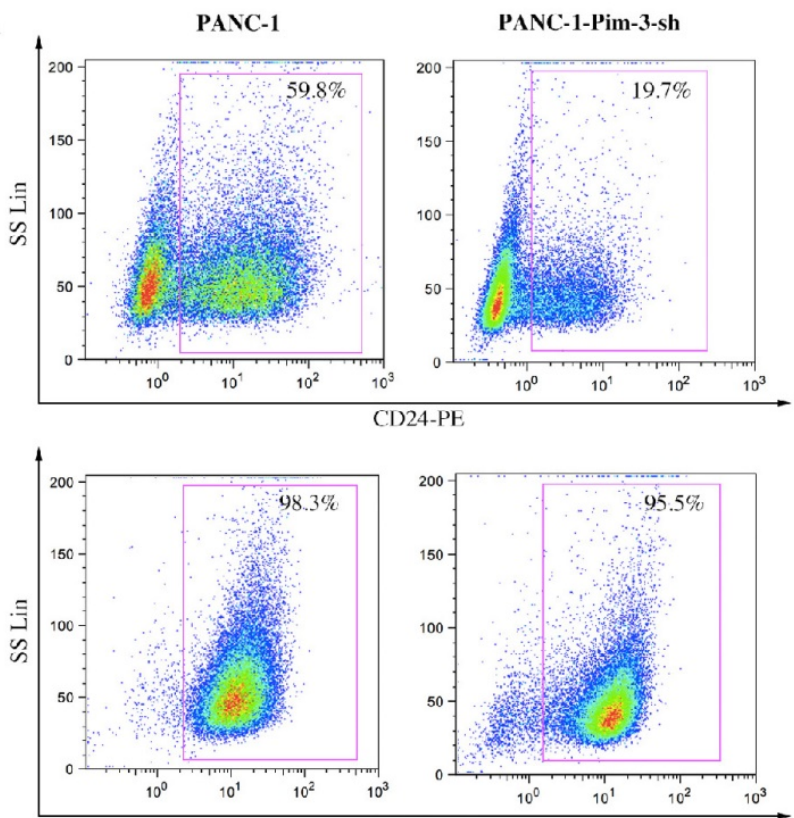

CD44-FITC
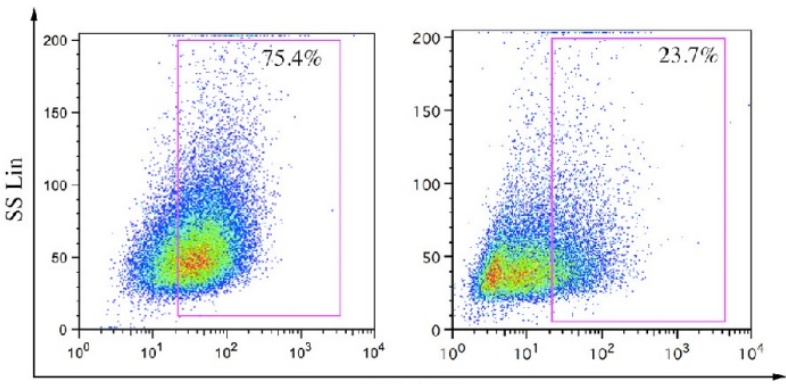

ESA-APC

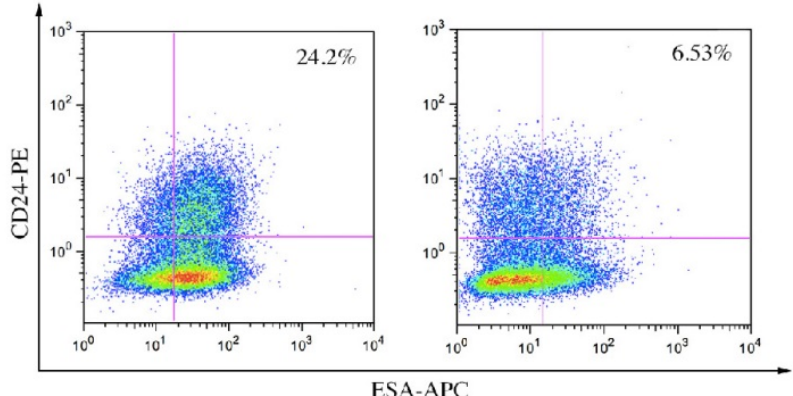

B

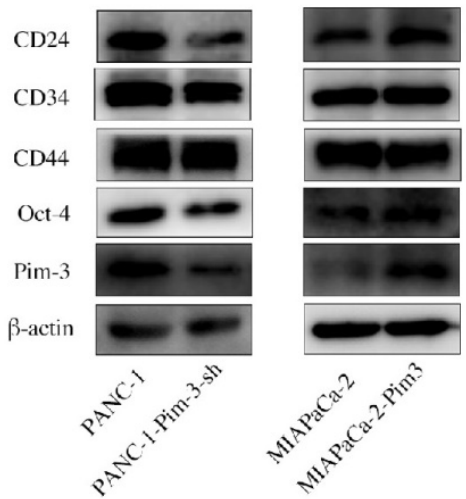

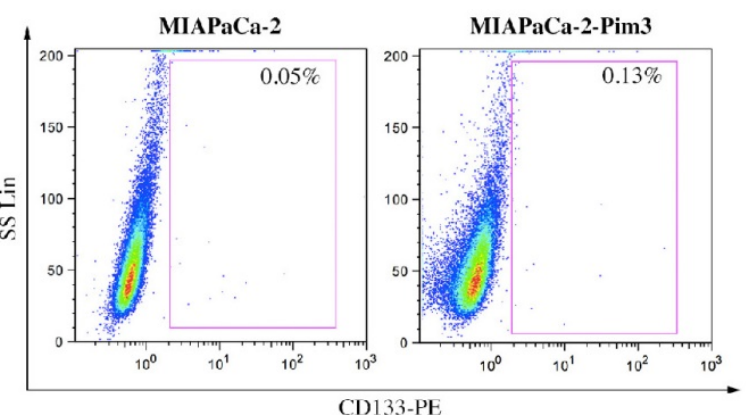
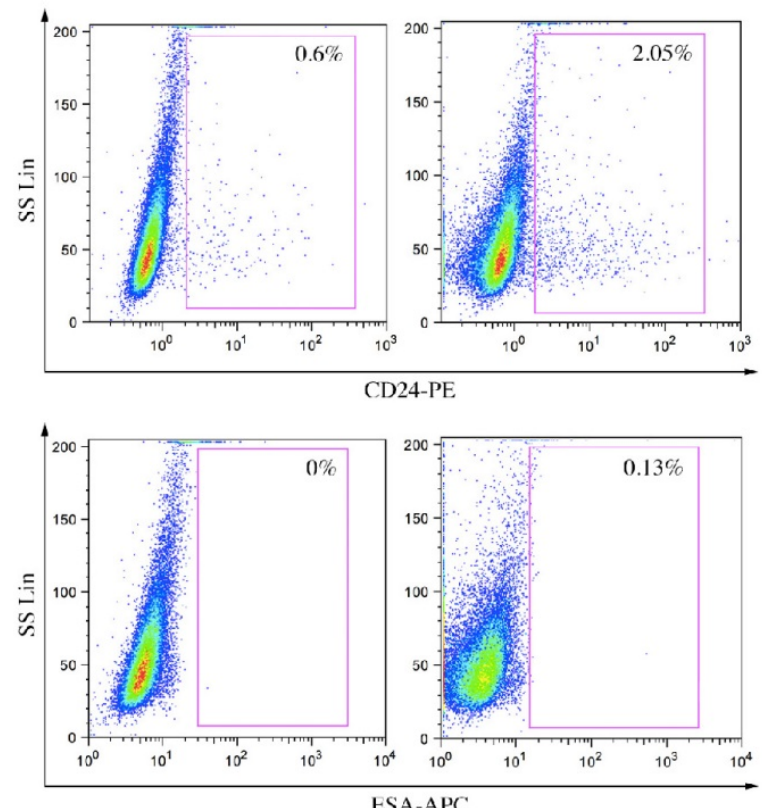

ESA-APC

C
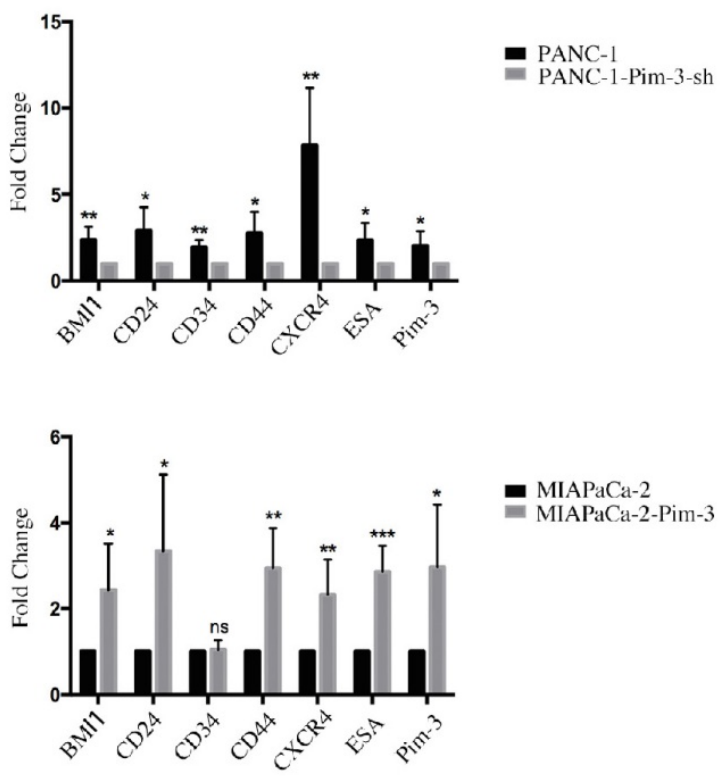
D
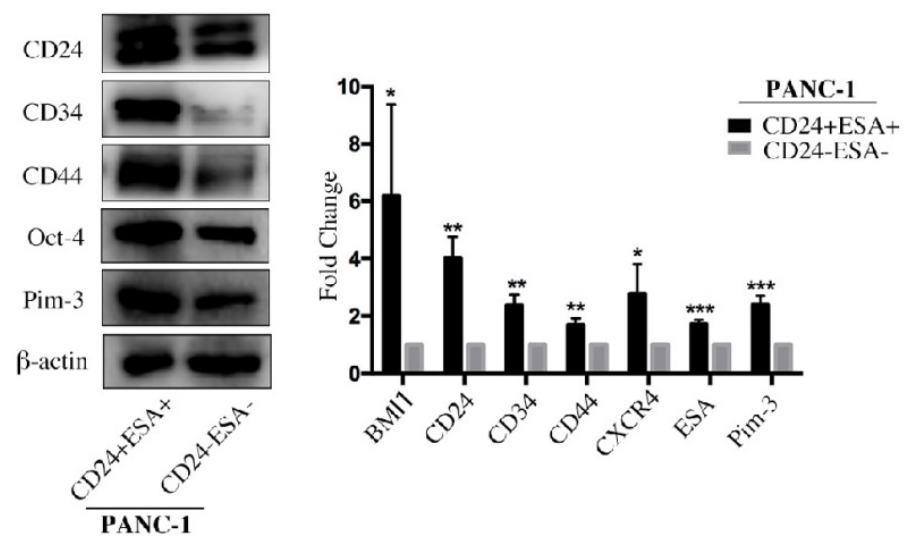

E
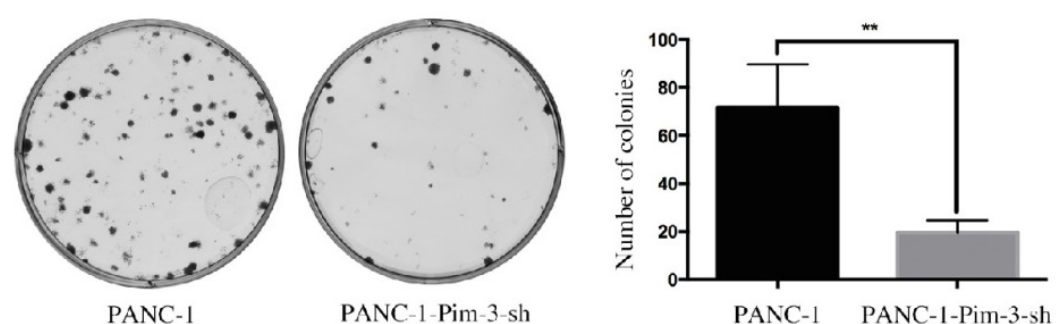

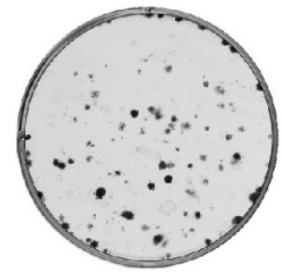

MIAPaCa-2

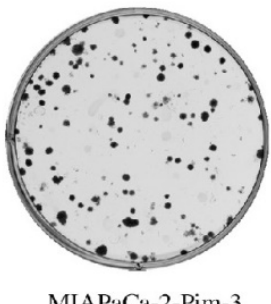

MIAPaCa-2-Pim-3

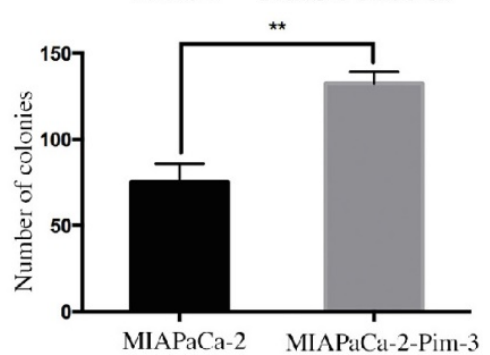

Figure 4. Pim-3 induces expression of stemness-associated markers in PC cells. A, Expression level of CD24, CD44 and ESA in PANC-1-Pim-3-sh and MIAPaCA-2-Pim3 analyzed by flow cytometry. Single positive cells (CD24+, CD44+ and ESA+) and their percentage in total cells were drawn in the rectangle gate. CD24+ESA+ cells were shown in the first quadrant as well as their percentage in total cells. B, Expression of other stemness-associated markers were examined in PANC-1-Pim-3-sh, MIAPaCA-2-Pim-3 and their parent cells at protein level by immunoblotting and $C$, mRNA level by quantitative RT-PCR (mean \pm SD; $n=3$; $* \mathrm{P}<0.05, * * \mathrm{P}<0.01, * * * \mathrm{P}<0.001)$. $\mathrm{D}$, Expression of Pim-3 and other stemness-associated markers were examined in CD24+ESA+ and CD24-ESA- PANC-1 cells at protein level by immunoblotting and mRNA level by quantitative RT-PCR (mean $\pm \mathrm{SD} ; \mathrm{n}=3 ; * \mathrm{P}<0.05, * * \mathrm{P}<0.01, * * * \mathrm{P}<0.001$ ). $\mathrm{E}$, Colonies formed by PANC-1-Pim-3-sh, MIAPaCA-2-Pim-3 and their parent cells. Data are presented as the mean \pm SD. The experiments were repeated three times. $* * P<0.01$.

Evidence for the existence of CSCs was first reported in human acute myeloid in the 1990s [30] and subsequently were identified in various solid tumors including breast cancer [31], brain tumor [32], prostate cancer [33], pancreatic cancer [6], ovarian cancer [34], etc. Currently, CSCs are usually isolated or enriched based on surface markers or by other methods such as ALDEFLUOR assay [35] and Hoechst 33342 dye exclusion assay [36]. As research continues, multiple novel surface markers are being used to isolate CSCs, which are not uniform across tumor types. Some markers may be shared by CSCs from different tumor types, such as CD44 and CD133. But, meanwhile, each tumor has its own unique markers, as highly tumorigenic breast cancer cells are CD24-, whereas pancreatic CSCs are identified as CD24+. Candidate CSC surface markers for PC consist of CD133, CXCR4 [37], CD24, CD44, ESA [6], c-Met
[38], ALDH [39], etc. Several CSC populations have been identified in PC based on these markers, but it is not clear how they are related to each other. Data from our study showed that there exists heterogeneity in expression levels of different stemness-associated markers in different PC cell lines and, consequently, specific markers should be chosen for specific cell lines according to their expression level. Based on data from flow cytometry analysis, we chose CD24 and ESA to isolate double positive and double negative cells from two PC cell lines (PANC-1 and MIAPaCa-2). In vitro and in vivo assays demonstrated that the double positive (CD24+ESA+) PC cells possessed higher self-renewal ability and tumorigenicity compared to double negative (CD24-ESA-) PC cells. Thus, we considered CD24+ESA+ PC cells as stem cell-like cells. 
A

pSTAT3

STAT3

Pim-3

$\beta$-actin

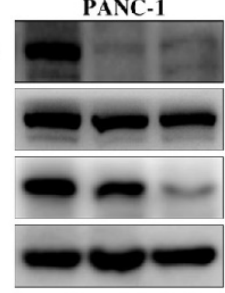

Control M-110 shPim-3

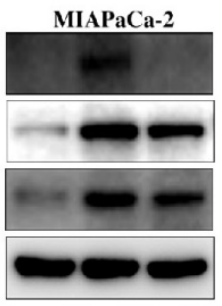

Control Pim-3 Pim-3+M-110
B

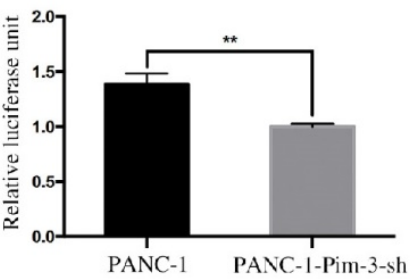

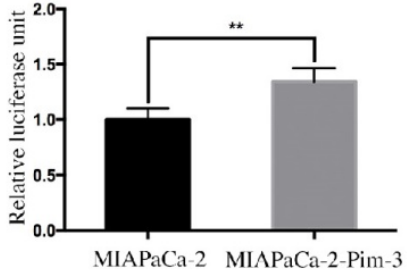

C

MIAPaCa-2-Pim-3

STAT3-siRNA

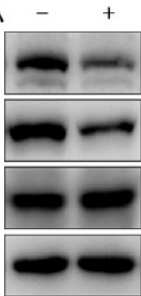

PANC-1-Pim-3-sh

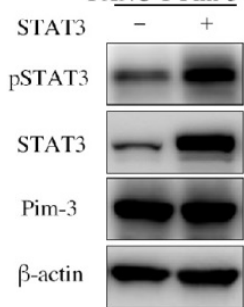

D
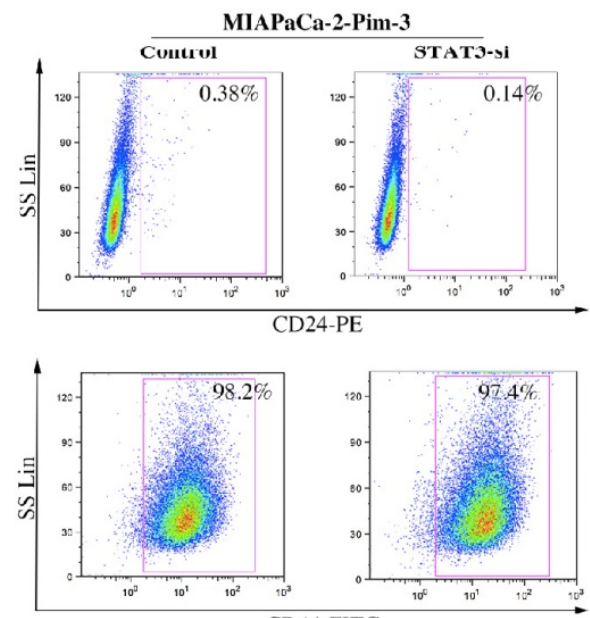

CD44-FITC

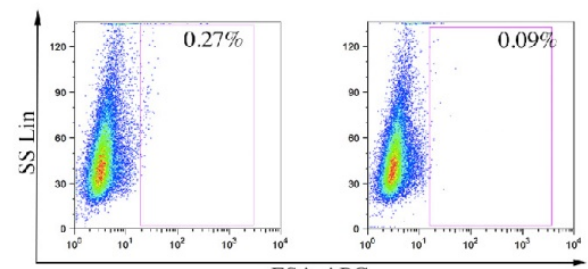

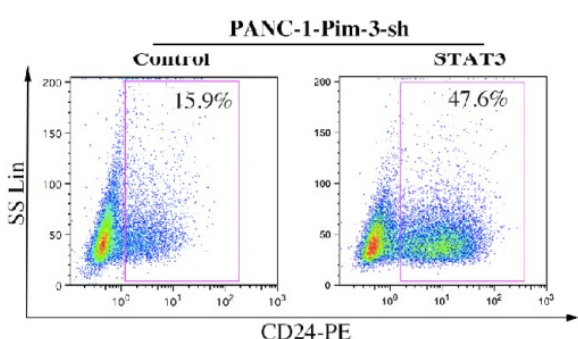

CD24-PE

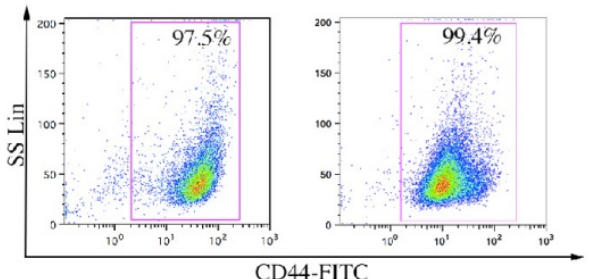

CD44-FITC

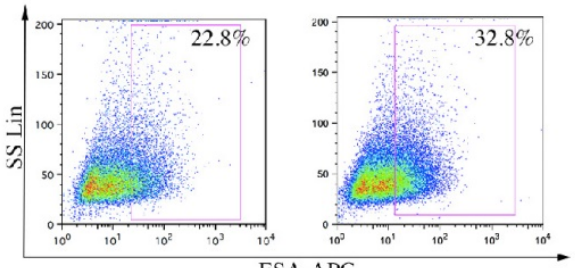

ESA-APC

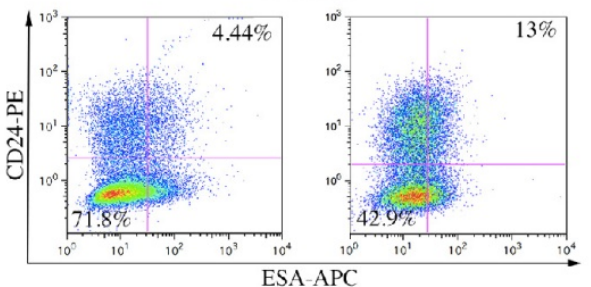

Figure 5. STAT3 mediates Pim-3-induced stemness in PC cells. $\boldsymbol{A}$, Expression level of pSTAT3 and total STAT3 were detected by immunoblotting in PANC-1-Pim-3-sh, MIAPaCa-2-Pim-3 and their parent cells as well as M-110 treated PANC-1 and MIAPaCa-2-Pim-3. $\beta$-actin was used as internal control. B, Transcriptional activity of STAT3 in PANC-1-Pim-3-sh, MIAPaCa-2-Pim-3 and their parent cells. Cells were co-transfected with a mixture of the STAT3 luciferase reporter and Renilla plasmid. After $48 \mathrm{~h}$, cells were harvested in passive lysis buffer and luciferase activity was assessed using a dual-luciferase assay system. Data are presented as normalized relative luciferase activity (mean $\pm S D ; n=3,{ }^{* *} p<0.01$ ). C, Expression levels of stemness-associated markers in MIAPaCa-2-Pim-3-STAT3-si and PANC-1-Pim-3-sh-STAT3 cells. MIAPaCa-2-Pim-3 was transiently transfected with STAT3 siRNA and PANC-1-Pim-3-sh was transiently transfected with STAT3 plasmid. Expression level of pSTAT3 and total STAT3 were detected by immunoblotting in MIAPaCa-2-Pim-3-STAT3-si and PANC-1-Pim-3-STAT3 cells. $\beta$-actin was used as internal control. D, Expression level of CD24, CD44 and ESA in MIAPaCa-2-Pim-3-STAT3-si and PANC-1-Pim-3-sh-STAT3 were analyzed by flow cytometry. Single positive cells (CD24+, CD44+ and ESA+) and their percentage in total cells were drawn in the rectangle gate. CD24+ESA+ PANC-1-Pim-3-sh cells were shown in the first quadrant as well as their percentage in total cells. 
In our study, we observed increased Pim-3 expression in CD24+ESA+ PC cells as well as other stemness-associated molecules including BMI1, CXCR4, Oct-4, etc. In addition to this, we also observed a positive correlation between Pim-3 and expression levels of several stemness-associated molecules in PC cells. Together, these findings provide direct and indirect support for the involvement of Pim-3 in PC CSCs. Apart from involvement in proliferation, survival, angiogenesis and apoptosis in PC, recent studies showed that Pim-3 is also involved in acquired gemcitabine resistance of PC and downregulation of Pim-3 expression sensitizes PC cells to gemcitabine toxicity $[15,16]$. Consistent with this, our study demonstrated that CD24+ESA+ PC cells were less sensitive to gemcitabine, which provides us new insight into Pim-3-induced therapy resistance.

In the present study, we associated STAT3, an oncogenic transcription factor, with Pim-3-induced overexpression of stemeness-associated markers. STAT3 has been reported to be frequently overexpressed in PC $[40,41]$ and play an important role in pancreatic carcinogenesis through regulating genes involved in proliferation, survival, angiogenesis and metastasis [42-44]. Its role in maintaining stem cell-like phenotypes has also been reported in various human cancers, including PC [45-49]. Besides maintenance of stemness in cancer cells, activation of STAT3 signaling pathway also plays an important role in converting non-CSCs to CSC [50]. Moreover, existing studies demonstrate a correlation between persistent expression of activated STAT3 and drug resistance in tumors including breast, ovarian and myeloma [51-53]. However, the precise molecular mechanisms responsible for activating STAT3 signaling pathway are not well understood. Our study suggests that Pim-3, as an upstream activator, enhances both phosphorylation and transcription of STAT3 to maintain stem cell-like phenotypes in PC, and utilization of M-110, a Pim-3 kinase inhibitor, could significantly downgrade the phosphorylation of STAT3. But the specific signaling pathways or molecules participating in Pim-3-mediated STAT3 activation remain to be further investigated in the future.

This study reveals the role of Pim-3 in maintaining stem cell-like phenotypes in PC for the first time, an effect mediated by activation of STAT3. Inhibitors of Pim-3 could effectively block this signaling axis. Based on these data, we hypothesize that development of novel therapeutic strategies targeting Pim-3 could not only help to eliminate the subpopulation of cells capable of self-renewal within PC, but also improve the efficacy of conventional therapies and then clinical outcomes for patients with PC.

\section{Supplementary Material}

Figure S1 and Table S1.

http://www.jcancer.org/v08p1530s1.pdf

\section{Abbreviations}

PC: pancreatic cancer; CSC: cancer stem cell; ESA: epithelial specific antigen; STAT3: signal transducer and activator of transcription 3.

\section{Acknowledgement}

This work was supported by the National Science Foundation of China (NSFC) (30973476, 81272727 , and 81472223).

\section{Ethics approval}

This study was approved by Committee on the Ethics of Animal Experiments of Fudan University and performed in strict accordance with the recommendations in the Guide for the Care and Use of Laboratory Animals of Fudan University.

\section{Competing Interests}

The authors have declared that no competing interest exists.

\section{References}

1. Siegel RL, Miller KD, Jemal A. Cancer statistics, 2016. CA Cancer J Clin. 2016; 66: 7-30.

2. Li D, Xie K, Wolff R, Abbruzzese JL. Pancreatic cancer. Lancet. 2004; 363: 1049-57.

3. Ansari D, Gustafsson A, Andersson R. Update on the management of pancreatic cancer: surgery is not enough. World journal of gastroenterology : WJG. 2015; 21: 3157-65.

4. Clarke MF, Dick JE, Dirks PB, Eaves CJ, Jamieson CH, Jones DL, et al. Cancer stem cells--perspectives on current status and future directions: AACR Workshop on cancer stem cells. Cancer research. 2006; 66: 9339-44.

5. Tanase CP, Neagu AI, Necula LG, Mambet C, Enciu AM, Calenic B, et al. Cancer stem cells: involvement in pancreatic cancer pathogenesis and perspectives on cancer therapeutics. World journal of gastroenterology : WJG. 2014; 20: 10790-801.

6. Li C, Heidt DG, Dalerba P, Burant CF, Zhang L, Adsay V, et al. Identification of pancreatic cancer stem cells. Cancer research. 2007; 67: 1030-7.

7. Bednar F, Simeone DM. Pancreatic cancer stem cells and relevance to cancer treatments. J Cell Biochem. 2009; 107: 40-5.

8. Li Y, Kong D, Ahmad A, Bao B, Sarkar FH. Pancreatic cancer stem cells: emerging target for designing novel therapy. Cancer Lett. 2013; 338: 94-100.

9. Li YY, Mukaida N. Pathophysiological roles of Pim-3 kinase in pancreatic cancer development and progression. World journal of gastroenterology : WJG. 2014; 20: 9392-404.

10. Fujii C, Nakamoto Y, Lu P, Tsuneyama K, Popivanova BK, Kaneko S, et al. Aberrant expression of serine/threonine kinase Pim-3 in hepatocellular carcinoma development and its role in the proliferation of human hepatoma cell lines. Int J Cancer. 2005; 114: 209-18.

11. Li YY, Popivanova BK, Nagai Y, Ishikura H, Fujii C, Mukaida N. Pim-3, a proto-oncogene with serine/threonine kinase activity, is aberrantly expressed in human pancreatic cancer and phosphorylates bad to block bad-mediated apoptosis in human pancreatic cancer cell lines. Cancer research. 2006; 66: 6741-7.

12. Zheng HC, Tsuneyama K, Takahashi H, Miwa S, Sugiyama T, Popivanova BK, et al. Aberrant Pim-3 expression is involved in gastric adenoma-adenocarcinoma sequence and cancer progression. J Cancer Res Clin Oncol. 2008; 134: 481-8.

13. Mukaida N, Wang YY, Li YY. Roles of Pim-3, a novel survival kinase, in tumorigenesis. Cancer Sci. 2011; 102: 1437-42. 
14. Wang C, Li HY, Liu B, Huang S, Wu L, Li YY. Pim-3 promotes the growth of human pancreatic cancer in the orthotopic nude mouse model through vascular endothelium growth factor. J Surg Res. 2013; 185: 595-604.

15. Xu D, Cobb MG, Gavilano L, Witherspoon SM, Williams D, White CD, et al. Inhibition of oncogenic Pim-3 kinase modulates transformed growth and chemosensitizes pancreatic cancer cells to gemcitabine. Cancer Biol Ther. 2013; 14: 492-501.

16. Liang $\mathrm{C}$, $\mathrm{Yu} \mathrm{XJ}$, Guo $\mathrm{XZ}$, Sun $\mathrm{MH}$, Wang $\mathrm{Z}$, Song $\mathrm{Y}$, et al. MicroRNA-33a-mediated downregulation of Pim-3 kinase expression renders human pancreatic cancer cells sensitivity to gemcitabine. Oncotarget. 2015; 6: 14440-55.

17. Chen XY, Wang Z, Li B, Zhang YJ, Li YY. Pim-3 contributes to radioresistance through regulation of the cell cycle and DNA damage repair in pancreatic cancer cells. Biochem Biophys Res Commun. 2016; 473: 296-302.

18. Aksoy I, Sakabedoyan C, Bourillot PY, Malashicheva AB, Mancip J, Knoblauch $\mathrm{K}$, et al. Self-renewal of murine embryonic stem cells is supported by the serine/threonine kinases Pim-1 and Pim-3. Stem Cells. 2007; 25: 2996-3004.

19. Lang MF, Yang S, Zhao C, Sun G, Murai K, Wu X, et al. Genome-wide profiling identified a set of miRNAs that are differentially expressed in glioblastoma stem cells and normal neural stem cells. PLoS One. 2012; 7: e36248.

20. Zhang F, Liu B, Wang Z, Yu XJ, Ni QX, Yang WT, et al. A novel regulatory mechanism of Pim-3 kinase stability and its involvement in pancreatic cancer progression. Mol Cancer Res. 2013; 11: 1508-20.

21. Maetzel D, Denzel S, Mack B, Canis M, Went P, Benk M, et al. Nuclear signalling by tumour-associated antigen EpCAM. Nat Cell Biol. 2009; 11: 162-71.

22. Osta WA, Chen Y, Mikhitarian K, Mitas M, Salem M, Hannun YA, et al. EpCAM is overexpressed in breast cancer and is a potential target for breast cancer gene therapy. Cancer research. 2004; 64: 5818-24.

23. Munz M, Kieu $C$, Mack B, Schmitt B, Zeidler $\mathrm{R}$, Gires $\mathrm{O}$, The carcinoma-associated antigen EpCAM upregulates c-myc and induces cell proliferation. Oncogene. 2004; 23: 5748-58.

24. Litvinov SV, van Driel W, van Rhijn CM, Bakker HA, van Krieken $\mathrm{H}$, Fleuren GJ, et al. Expression of Ep-CAM in cervical squamous epithelia correlates with an increased proliferation and the disappearance of markers for terminal differentiation. Am J Pathol. 1996; 148: 865-75.

25. Burris HA, 3rd, Moore MJ, Andersen J, Green MR, Rothenberg ML, Modiano $\mathrm{MR}$, et al. Improvements in survival and clinical benefit with gemcitabine as first-line therapy for patients with advanced pancreas cancer: a randomized trial. J Clin Oncol. 1997; 15: 2403-13.

26. Chang M, Kanwar N, Feng E, Siu A, Liu X, Ma D, et al. PIM kinase inhibitors downregulate STAT3(Tyr705) phosphorylation. Molecular cancer therapeutics. 2010; 9: 2478-87.

27. Fryer RA, Galustian C, Dalgleish AG. Recent advances and developments in treatment strategies against pancreatic cancer. Current clinical pharmacology. 2009; 4: 102-12.

28. Liu QH, Zhang J, Zhao CY, Yu DH, Bu HJ, Chen Y, et al. Surviving cells after treatment with gemcitabine or 5-fluorouracil for the study of de novo resistance of pancreatic cancer. Cancer Lett. 2012; 314: 119-25.

29. Raj D, Aicher A, Heeschen C. Concise Review: Stem Cells in Pancreatic Cancer: From Concept to Translation. Stem Cells. 2015; 33: 2893-902.

30. Bonnet D, Dick JE. Human acute myeloid leukemia is organized as a hierarchy that originates from a primitive hematopoietic cell. Nature medicine. 1997; 3: 730-7.

31. Al-Hajj M, Wicha MS, Benito-Hernandez A, Morrison SJ, Clarke MF. Prospective identification of tumorigenic breast cancer cells. Proceedings of the National Academy of Sciences of the United States of America. 2003; 100: 3983-8.

32. Singh SK, Clarke ID, Terasaki M, Bonn VE, Hawkins C, Squire J, et al. Identification of a cancer stem cell in human brain tumors. Cancer research. 2003; 63: 5821-8.

33. Collins AT, Berry PA, Hyde C, Stower MJ, Maitland NJ. Prospective identification of tumorigenic prostate cancer stem cells. Cancer research. 2005; 65: 10946-51.

34. Bapat SA, Mali AM, Koppikar CB, Kurrey NK. Stem and progenitor-like cells contribute to the aggressive behavior of human epithelial ovarian cancer. Cancer research. 2005; 65: 3025-9.

35. Corti S, Locatelli F, Papadimitriou D, Donadoni C, Salani S, Del Bo R, et al. Identification of a primitive brain-derived neural stem cell population based on aldehyde dehydrogenase activity. Stem Cells. 2006; 24: 975-85.

36. Gou S, Liu T, Wang C, Yin T, Li K, Yang M, et al. Establishment of clonal colony-forming assay for propagation of pancreatic cancer cells with stem cell properties. Pancreas. 2007; 34: 429-35.

37. Hermann PC, Huber SL, Herrler T, Aicher A, Ellwart JW, Guba M, et al. Distinct populations of cancer stem cells determine tumor growth and metastatic activity in human pancreatic cancer. Cell stem cell. 2007; 1: 313-23.

38. Li C, Wu JJ, Hynes M, Dosch J, Sarkar B, Welling TH, et al. c-Met is a marker of pancreatic cancer stem cells and therapeutic target. Gastroenterology. 2011; 141: 2218-27 e5.

39. Ginestier C, Hur MH, Charafe-Jauffret E, Monville F, Dutcher J, Brown M, et al. ALDH1 is a marker of normal and malignant human mammary stem cells and a predictor of poor clinical outcome. Cell stem cell. 2007; 1: 555-67.

40. Scholz A, Heinze S, Detjen KM, Peters M, Welzel M, Hauff P, et al. Activated signal transducer and activator of transcription 3 (STAT3) supports the malignant phenotype of human pancreatic cancer. Gastroenterology. 2003; 125: 891-905.

41. Toyonaga T, Nakano K, Nagano M, Zhao G, Yamaguchi K, Kuroki S, et al. Blockade of constitutively activated Janus kinase/signal transducer and activator of transcription-3 pathway inhibits growth of human pancreatic cancer. Cancer Lett. 2003; 201: 107-16.

42. Wei D, Le X, Zheng L, Wang L, Frey JA, Gao AC, et al. Stat3 activation regulates the expression of vascular endothelial growth factor and human pancreatic cancer angiogenesis and metastasis. Oncogene. 2003; 22: 319-29.

43. Qiu Z, Huang C, Sun J, Qiu W, Zhang J, Li H, et al. RNA interference-mediated signal transducers and activators of transcription 3 gene silencing inhibits invasion and metastasis of human pancreatic cancer cells. Cancer Sci. 2007; 98: 1099-106.

44. Fofaria NM, Srivastava SK. STAT3 induces anoikis resistance, promotes cell invasion and metastatic potential in pancreatic cancer cells. Carcinogenesis. 2015; 36: 142-50.

45. Lin L, Fuchs J, Li C, Olson V, Bekaii-Saab T, Lin J. STAT3 signaling pathway is necessary for cell survival and tumorsphere forming capacity in $\mathrm{ALDH}(+) / \mathrm{CD} 133(+)$ stem cell-like human colon cancer cells. Biochem Biophys Res Commun. 2011; 416: 246-51.

46. Jiang J, Li Z, Yu C, Chen M, Tian S, Sun C. MiR-1181 inhibits stem cell-like phenotypes and suppresses SOX2 and STAT3 in human pancreatic cancer. Cancer Lett. 2015; 356: 962-70.

47. Yin X, Zhang BH, Zheng SS, Gao DM, Qiu SJ, Wu WZ, et al. Coexpression of gene Oct4 and Nanog initiates stem cell characteristics in hepatocellular carcinoma and promotes epithelial-mesenchymal transition through activation of Stat3/Snail signaling. J Hematol Oncol. 2015; 8: 23.

48. Im CN, HyeonYun H, Song B, Youn DY, Cui MN, Kim HS, et al. BIS-mediated STAT3 stabilization regulates glioblastoma stem cell-like phenotypes. Oncotarget. 2016.

49. Tyagi N, Marimuthu S, Bhardwaj A, Deshmukh SK, Srivastava SK, Singh AP, et al. p-21 activated kinase 4 (PAK4) maintains stem cell-like phenotypes in pancreatic cancer cells through activation of STAT3 signaling. Cancer Lett. 2016; 370: 260-7

50. Kim SY, Kang JW, Song X, Kim BK, Yoo YD, Kwon YT, et al. Role of the IL-6-JAK1-STAT3-Oct-4 pathway in the conversion of non-stem cancer cells into cancer stem-like cells. Cell Signal. 2013; 25: 961-9.

51. Catlett-Falcone R, Landowski TH, Oshiro MM, Turkson J, Levitzki A, Savino $\mathrm{R}$, et al. Constitutive activation of Stat 3 signaling confers resistance to apoptosis in human U266 myeloma cells. Immunity. 1999; 10: 105-15.

52. Duan Z, Foster R, Bell DA, Mahoney J, Wolak K, Vaidya A, et al. Signal transducers and activators of transcription 3 pathway activation in drug-resistant ovarian cancer. Clinical cancer research : an official journal of the American Association for Cancer Research. 2006; 12: 5055-63.

53. Gritsko T, Williams A, Turkson J, Kaneko S, Bowman T, Huang M, et al. Persistent activation of stat 3 signaling induces survivin gene expression and confers resistance to apoptosis in human breast cancer cells. Clinical cancer research : an official journal of the American Association for Cancer Research. 2006 ; 12 : $11-9$ 